\title{
Comparison of the anticonvulsant potency of various diuretic drugs in the maximal electroshock-induced seizure threshold test in mice
}

\author{
Katarzyna Załuska ${ }^{1, B-D}$, Maria W. Kondrat-Wróbel ${ }^{1, B-D}$, Jarogniew J. Łuszczki, ${ }^{1,2, A, C-F}$ \\ ${ }^{1}$ Department of Pathophysiology, Medical University of Lublin, Poland \\ ${ }^{2}$ Isobolographic Analysis Laboratory, Institute of Rural Health, Lublin, Poland \\ A - research concept and design; $\mathrm{B}$ - collection and/or assembly of data; $\mathrm{C}$ - data analysis and interpretation; \\ $D$ - writing the article; $E$ - critical revision of the article; $F$ - final approval of the article
}

\section{Address for correspondence \\ Jarogniew J. Łuszczki}

E-mail: jarogniew.luszzzki@umlub.pl

\section{Funding sources}

None declared

\section{Conflict of interest}

Prof. J.J. Łuszzzki has been involved in the design and development of new antiepileptics and CNS drugs. He has received, within the last 5 years, an unrestricted research grant from GlaxoSmithKline (Brentford, UK). The remaining authors have no conflict of interest to disclose.

\section{Acknowledgements}

This study was supported by grants from the Medical University of Lublin (DS 474/2012-2014 and DS 474/2015-2016).

Received on June 14, 2016 Reviewed on 0ctober 1, 2016 Accepted on January 27, 2017
DOI

10.17219/acem/68694

\section{Copyright}

Copyright by Author(s)

This is an article distributed under the terms of the Creative Commons Attribution Non-Commercial License (http://creativecommons.org/licenses/by-nc-nd/4.0/)

\begin{abstract}
Background. The coexistence of seizures and arterial hypertension requires an adequate and efficacious treatment involving both protection from seizures and reduction of high arterial blood pressure. Accumulating evidence indicates that some diuretic drugs (with a well-established position in the treatment of arterial hypertension) also possess anticonvulsant properties in various experimental models of epilepsy.

Objectives. The aim of this study was to assess the anticonvulsant potency of 6 commonly used diuretic drugs (i.e., amiloride, ethacrynic acid, furosemide, hydrochlorothiazide, indapamide, and spironolactone) in the maximal electroshock-induced seizure threshold (MEST) test in mice.

Material and methods. Doses of the studied diuretics and their corresponding threshold increases were linearly related, allowing for the determination of doses which increase the threshold for electroconvulsions in drug-treated animals by $20 \%$ ( $\mathrm{TID}_{20}$ values) over the threshold in control animals.

Results. Amiloride, hydrochlorothiazide and indapamide administered systemically (intraperitoneally - i.p.) increased the threshold for maximal electroconvulsions in mice, and the experimentally-derived $\mathrm{TID}_{20}$ values in the maximal electroshock seizure threshold test were $30.2 \mathrm{mg} / \mathrm{kg}$ for amiloride, $68.2 \mathrm{mg} / \mathrm{kg}$ for hydrochlorothiazide and $3.9 \mathrm{mg} / \mathrm{kg}$ for indapamide. In contrast, ethacrynic acid (up to $100 \mathrm{mg} / \mathrm{kg}$ ), furosemide (up to $100 \mathrm{mg} / \mathrm{kg}$ ) and spironolactone (up to $50 \mathrm{mg} / \mathrm{kg}$ ) administered i.p. had no significant impact on the threshold for electroconvulsions in mice.

Conclusions. The studied diuretics can be arranged with respect to their anticonvulsant potency in the MEST test as follows: indapamide > amiloride > hydrochlorothiazide. No anticonvulsant effects were observed for ethacrynic acid, furosemide or spironolactone in the MEST test in mice.
\end{abstract}

Key words: diuretic drugs, threshold for electroconvulsions, $\mathrm{TID}_{20}$ values 


\section{Introduction}

Arterial hypertension is the most common cardiovascular disease affecting approx. $26 \%$ of the worldwide population, and thus, it is a major public health problem in both developed and developing countries. ${ }^{1}$ In contrast, epilepsy is a serious neurological disorder affecting approx. $1 \%$ of the population in every country throughout the world. ${ }^{2}$ The coexistence of both diseases (seizures and hypertension) requires adequate and efficacious treatment which simultaneously protects against seizures and reduces arterial blood pressure. In such cases, a combined treatment of antihypertensive and antiepileptic drugs is prescribed for these patients. However, any combined pharmacotherapy is associated with the appearance of interactions, whose nature may be pharmacodynamic, pharmacokinetic, or mixed. ${ }^{3}$ The most notable group of drugs with a well-established position in the treatment of arterial hypertension are diuretics. ${ }^{4}$

Accumulating experimental evidence indicates that some diuretic drugs also possess anticonvulsant properties in various experimental models of epilepsy. ${ }^{5-8}$ Previously, it was discovered that amiloride, hydrochlorothiazide and indapamide (3 classical diuretics) elevated the threshold for maximal electroconvulsions in experimental animals. ${ }^{9-11}$ Unfortunately, the anticonvulsant properties of the diuretics were not directly compared to each other. However, to unequivocally assess the anticonvulsant potential of agents or drugs that increase the threshold for electroconvulsions, Swinyard et al. recommended determining doses of the compounds that increase the electroconvulsive threshold in drug-treated animals $20 \%$ over the threshold in control animals (i.e., TID $_{20}$ values). ${ }^{12}$ Thus, the TID $_{20}$ values allow researchers to precisely assess the anticonvulsant potency of drugs or agents in preclinical studies. ${ }^{12,13}$

Considering the abovementioned facts, it was of pivotal importance to determine the $\mathrm{TID}_{20}$ values for 6 commonly prescribed diuretics (i.e., furosemide, spironolactone, amiloride, ethacrynic acid, hydrochlorothiazide, and indapamide) in the maximal electroshock-induced seizure threshold (MEST) test in mice in order to assess their anticonvulsant potency in this seizure model. There is no doubt that diuretic drugs with anticonvulsant properties can be preferentially recommended for patients with both high arterial blood pressure and seizures.

\section{Material and methods}

\section{Animals and experimental conditions}

Experiments were performed on adult male albino Swiss mice weighing 22-26 g. The experimental protocol described in this study conformed to the "Guide for the Care and Use of Laboratory Animals" and was approved by the Local Ethics Committee. ${ }^{14}$

\section{Drugs}

Ethacrynic acid, indapamide and spironolactone (all 3 drugs from Sigma-Aldrich, Poznań, Poland) as well as hydrochlorothiazide (Polpharma S.A., Starogard Gdański, Poland) were suspended in a $1 \%$ solution of Tween 80 (Sigma-Aldrich) in distilled water. Amiloride hydrochloride hydrate (Sigma-Aldrich) and furosemide (for injection $10 \mathrm{mg} / \mathrm{mL}$; Polpharma S.A.) were dissolved in distilled water. All diuretic drugs were administered intraperitoneally (i.p.) in a volume of $0.005 \mathrm{~mL} / \mathrm{g}$ body weight as follows: ethacrynic acid and furosemide at $30 \mathrm{~min}$ before the MEST-induced seizures, amiloride at $60 \mathrm{~min}$ before, and hydrochlorothiazide, indapamide and spironolactone at $120 \mathrm{~min}$ before.

\section{Maximal electroshock seizure threshold test and the calculation of threshold increasing doses by $20 \%\left(\mathrm{TID}_{20}\right)$ values}

Seizure activity (electroconvulsions) was evoked by a current (sine-wave, $0.2 \mathrm{~s}$ stimulus duration, $50 \mathrm{~Hz}, 500 \mathrm{~V}$ ) delivered via auricular electrodes by a Rodent Shocker generator (Hugo Sachs Elektronik, Freiburg, Germany). ${ }^{15}$ To assess the threshold for maximal electroconvulsions, 4 groups of mice (8 mice per group) were subjected to electroshocks of varying intensities (ranging from 4 to $10 \mathrm{~mA}$ ) to yield seizures in $10-30 \%, 30-50 \%, 50-70 \%$, and $70-90 \%$ of animals. The log-probit method was used to calculate the median current strength $\left(\mathrm{CS}_{50}[\mathrm{~mA}]\right)$, representing the current intensity necessary to induce tonic hind limb extension in $50 \%$ of the mice challenged. ${ }^{16}$ The threshold $\left(\mathrm{CS}_{50}\right.$ values) for maximal electroconvulsions in mice receiving amiloride, ethacrynic acid, furosemide, hydrochlorothiazide, indapamide, and spironolactone (all diuretics in increasing doses), were experimentally determined as described in detail previously. ${ }^{17,18}$ Subsequently, the percentage of increase in $\mathrm{CS}_{50}$ values for animals injected with increasing doses of diuretics over the control $\mathrm{CS}_{50}$ value was calculated. The doses of diuretics and their resultant percentage of threshold increase over the control were graphically plotted in rectangular coordinates of the Cartesian plot system and examined with the least-squares linear regression analysis. From linear regression equations, the $\mathrm{TID}_{20}$ values were calculated as recommended earlier. ${ }^{12,13}$

\section{Statistics}

The $\mathrm{CS}_{50}$ values with their standard error of mean (SEM) were statistically analyzed with one-way analysis of variance (ANOVA) followed by the Tukey-Kramer post-hoc test. Differences among values were considered statistically significant if $\mathrm{p}<0.05$. 


\section{Results}

\section{Effects of various diuretic drugs on the threshold for maximal electroshock-induced seizures}

Amiloride administered systemically (i.p.) at doses of 5, $10,50,75$, and $100 \mathrm{mg} / \mathrm{kg}$ elevated the threshold for MESTinduced seizures over the controls by $11.2 \%, 12.7 \%, 24.2 \%$, $37.2 \%$, and $51.2 \%$, respectively (Table 1 ). With one-way ANOVA and the Tukey-Kramer post-hoc test, only amiloride $(100 \mathrm{mg} / \mathrm{kg})$ significantly raised $(\mathrm{p}<0.05)$ the threshold for electroconvulsions in mice $(\mathrm{f}(5 ; 90)=2.889 ; \mathrm{p}=0.0182)$ (Table 1). Similarly, hydrochlorothiazide administered i.p. at doses of 25, 50 and $100 \mathrm{mg} / \mathrm{kg}$ increased the threshold for maximal electroconvulsions by $11.5 \%, 15.4 \%$ and $26.9 \%$, respectively (Table 1). Statistical analysis of data with oneway ANOVA revealed that hydrochlorothiazide $(100 \mathrm{mg} /$ $\mathrm{kg})$ significantly elevated $(\mathrm{p}<0.05)$ the electroconvulsive threshold in mice $(\mathrm{f}(3 ; 76)=2.535 ; \mathrm{p}=0.0631)($ Table 1$)$. Moreover, indapamide administered i.p. at doses of 1.5, 3 and $6 \mathrm{mg} / \mathrm{kg}$ raised the threshold for MEST-induced seizures by $2.2 \%, 12.1 \%$ and $37.4 \%$, respectively (Table 1 ). In this case, indapamide $(6 \mathrm{mg} / \mathrm{kg})$ significantly increased $(\mathrm{p}<0.05)$ the threshold for electroconvulsions in mice $(\mathrm{f}(3 ; 60)=3.718 ; \mathrm{p}=0.0161)$ (Table 1$)$. In the case of ethacrynic acid, the drug at a maximally tested dose of $100 \mathrm{mg} / \mathrm{kg}$ elevated the threshold only by $5.9 \%$, which was not statistically significant (Table 1). In contrast, furosemide and spironolactone (both at a maximally tested dose of $100 \mathrm{mg} / \mathrm{kg}$ ) decreased the threshold for electroconvulsions in experimental animals in the MEST test. The observed changes, however, were not statistically significant (Table 1).

Subsequently, the doses of amiloride, hydrochlorothiazide and indapamide were linearly related to the threshold increases, and the respective equations describing these relations are illustrated in Fig. 1. The experimentally-derived $\mathrm{TID}_{20}$ values in the MEST test in mice were $30.2 \mathrm{mg} / \mathrm{kg}$

Table 1. Influence of 6 diuretic drugs in the maximal electroshock seizure threshold test in mice

\begin{tabular}{|c|c|c|c|c|}
\hline Drug $[\mathrm{mg} / \mathrm{kg}]$ & $\mathrm{CS}_{50}[\mathrm{~mA}]$ & $\mathrm{n}$ & $\mathrm{TI}[\%]$ & One-way ANOVA \\
\hline Control & $5.92 \pm 0.77$ & 16 & - & \multirow{6}{*}{$\begin{array}{c}f(5 ; 90)=2.889 \\
p=0.0182\end{array}$} \\
\hline Amiloride (5) & $6.58 \pm 0.59$ & 16 & 11.2 & \\
\hline Amiloride (10) & $6.67 \pm 0.61$ & 24 & 12.7 & \\
\hline Amiloride (50) & $7.35 \pm 0.45$ & 8 & 24.2 & \\
\hline Amiloride (75) & $8.12 \pm 0.72$ & 16 & 37.2 & \\
\hline Amiloride (100) & $8.95 \pm 0.53^{*}$ & 16 & 51.2 & \\
\hline Control & $6.8 \pm 0.61$ & 24 & - & \multirow{3}{*}{$\begin{array}{c}f(2 ; 53)=0.0976 \\
p=0.9072\end{array}$} \\
\hline Ethacrynic acid (50) & $7.0 \pm 0.72$ & 16 & 2.9 & \\
\hline Ethacrynic acid (100) & $7.2 \pm 0.62$ & 16 & 5.9 & \\
\hline Control & $4.89 \pm 0.40$ & 16 & - & \multirow{3}{*}{$\begin{array}{c}f(2 ; 45)=0.0168 \\
p=0.9833\end{array}$} \\
\hline Furosemide (50) & $4.76 \pm 0.45$ & 8 & 2.7 & \\
\hline Furosemide (100) & $4.84 \pm 0.36$ & 24 & 1.0 & \\
\hline Control & $5.2 \pm 0.37$ & 16 & - & \multirow{4}{*}{$\begin{array}{c}f(3 ; 76)=2.535 \\
p=0.0631\end{array}$} \\
\hline Hydrochlorothiazide (25) & $5.8 \pm 0.29$ & 24 & 11.5 & \\
\hline Hydrochlorothiazide (50) & $6.0 \pm 0.35$ & 16 & 15.4 & \\
\hline Hydrochlorothiazide (100) & $6.6 \pm 0.40^{*}$ & 24 & 26.9 & \\
\hline Control & $5.54 \pm 0.42$ & 16 & - & \multirow{4}{*}{$\begin{array}{c}f(3 ; 60)=3.718 \\
p=0.0161\end{array}$} \\
\hline Indapamide (1.5) & $5.66 \pm 0.51$ & 16 & 2.2 & \\
\hline Indapamide (3.0) & $6.21 \pm 0.48$ & 16 & 12.1 & \\
\hline Indapamide (6.0) & $7.61 \pm 0.55^{*}$ & 16 & 37.4 & \\
\hline Control & $5.5 \pm 0.47$ & 16 & - & \multirow{6}{*}{$\begin{array}{c}f(5 ; 74)=0.2891 \\
p=0.9176\end{array}$} \\
\hline Spironolactone (12.5) & $5.4 \pm 0.42$ & 8 & -1.8 & \\
\hline Spironolactone (25) & $5.2 \pm 0.35$ & 24 & -5.5 & \\
\hline Spironolactone (37.5) & $5.1 \pm 0.45$ & 8 & -7.3 & \\
\hline Spironolactone (50) & $5.0 \pm 0.40$ & 16 & -9.1 & \\
\hline Spironolactone (100) & $4.8 \pm 0.46$ & 8 & -12.7 & \\
\hline
\end{tabular}

Results are median current strengths $\left(\mathrm{CS}_{50}[\mathrm{~mA}] \pm \mathrm{SEM}\right)$ necessary to produce tonic convulsions in $50 \%$ of the animals tested; control groups of animals received a vehicle ( $1 \%$ of solution of Tween 80 in distilled water); $n$ - number of animals tested at those current strength intensities whose seizure effects ranged between $16 \%$ and $84 \%$; $\mathrm{Tl}$ - threshold increasing values are presented as percentage of increase in $\mathrm{CS}_{50}$ values for animals injected with increasing doses of diuretics over the control (vehicle-treated) animals; statistical analysis of data was performed with one-way ANOVA followed by the Tukey-Kramer post-hoc test; ${ }^{*} p<0.05$ vs the control (vehicle-treated) animals. 


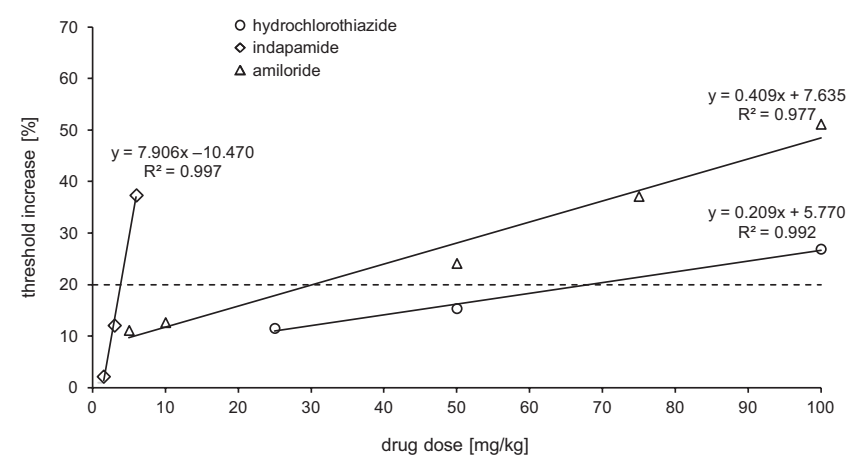

Fig. 1. Linear regression analysis of doses of various diuretic drugs and their corresponding threshold increases in the MEST test in mice

$y$ - threshold increase [\%]; $x$ - dose of the diuretic; R2 - coefficient of determination. The dashed line reflects the TID20 values (threshold increasing doses by 20\%) in the MEST test.

for amiloride, $68.2 \mathrm{mg} / \mathrm{kg}$ for hydrochlorothiazide and $3.9 \mathrm{mg} / \mathrm{kg}$ for indapamide, respectively.

\section{Discussion}

Results indicate that there was a close correlation between the doses of 3 diuretic drugs (i.e., amiloride, hydrochlorothiazide and indapamide) and their anticonvulsant properties in mice subjected to the MEST test. In this study, linear regression analysis allowed for the determination of the $\mathrm{TID}_{20}$ values for amiloride, hydrochlorothiazide and indapamide. In the case of ethacrynic acid, the drug had no impact on the threshold for electroconvulsions. In contrast, furosemide and spironolactone diminished the threshold for electroconvulsions in mice, although the data did not reach the level of statistical significance.

Of note, the $\mathrm{TID}_{20}$ values presented in this study for diuretic drugs can be readily compared to those reported earlier for some second-generation antiepileptic drugs (AEDs). The TID 20 values for some AEDs were as follows: $70 \mathrm{mg} / \mathrm{kg}$ for gabapentin, ${ }^{18} 44 \mathrm{mg} / \mathrm{kg}$ for levetiracetam, ${ }^{19} 103.2 \mathrm{mg} / \mathrm{kg}$ for stiripentol, ${ }^{20} 4.4 \mathrm{mg} / \mathrm{kg}$ for tiagabine, ${ }^{17}$ and $226.2 \mathrm{mg} / \mathrm{kg}$ for vigabatrin. ${ }^{17,18} \mathrm{~A}$ direct comparison of $\mathrm{TID}_{20}$ values of the second-generation AEDs with those calculated for the 3 diuretics revealed that indapamide has the lowest $\mathrm{TID}_{20}$ value $(3.9 \mathrm{mg} / \mathrm{kg})$. In contrast, gabapentin, levetiracetam, stiripentol, and vigabatrin have higher $\mathrm{TID}_{20}$ values than those calculated for amiloride $(30.2 \mathrm{mg} / \mathrm{kg})$. In the case of hydrochlorothiazide, its $\mathrm{TID}_{20}$ value $(68.2 \mathrm{mg} / \mathrm{kg})$ is lower than that of gabapentin, stiripentol and vigabatrin in the MEST test. Thus, considering the anticonvulsant potency of the studied diuretics, the drugs can be arranged from the lowest to the highest $\mathrm{TID}_{20}$ values as follows: indapamide $>$ amiloride $>$ hydrochlorothiazide. This comparative study allowed for the assessment of the most favorable diuretic drug with the lowest $\mathrm{TID}_{20}$ value (indapamide), which is effective in suppressing MESTinduced tonic seizures in experimental animals.
There is another fact worth keeping in mind while translating the results from this study to a clinical setting. Since the $\mathrm{TID}_{20}$ value for indapamide in mice was $3.9 \mathrm{mg} / \mathrm{kg}$, it can be readily converted to a dose of indapamide used in humans, according to the method presented by Reagan-Shaw et al. ${ }^{21}$ The converted dose of indapamide for a $60 \mathrm{~kg}$ human should be $18.72 \mathrm{mg}$ (i.e., $0.312 \mathrm{mg} / \mathrm{kg}$ of body weight). The recommended maximum daily dose of indapamide in humans is $5 \mathrm{mg} .{ }^{22}$ Thus, it seems that the anticonvulsant effects of indapamide would appear if the daily dose of indapamide exceeded $\sim 4$ times the recommended maximum. Similarly, the $\mathrm{TID}_{20}$ values for amiloride and hydrochlorothiazide were $30.2 \mathrm{mg} / \mathrm{kg}$ and $68.2 \mathrm{mg} / \mathrm{kg}$, respectively. Thus, the corresponding doses of the diuretics in a $60 \mathrm{~kg}$ human should amount to $145 \mathrm{mg}$ for amiloride and $327.4 \mathrm{mg}$ for hydrochlorothiazide. The recommended maximum daily dose of amiloride is $20 \mathrm{mg},{ }^{23}$ and for hydrochlorothiazide it is $100 \mathrm{mg},{ }^{24}$ so the anticonvulsant effects of amiloride would be expected if the daily dose exceeded $\sim 7$ times the recommended maximum, and that of hydrochlorothiazide $\sim 3$ times. We are fully aware of such limitations in translational studies. However, it has to be noted that diuretic drugs cannot be used alone as anticonvulsant agents in patients with epilepsy, but always in combination with classical and novel AEDs in order to provide epilepsy patients with the most effective treatment against both arterial hypertension and seizures. Obviously, combinations of diuretics and AEDs always produce interactions of a pharmacodynamic, pharmacokinetic, or mixed nature. ${ }^{3}$ However, preclinical studies on animals allowed us to characterize the interactions between diuretics and AEDs. For instance, it has been reported that indapamide significantly potentiated the anticonvulsant action of carbamazepine, phenobarbital and valproate, although the effects observed for phenobarbital in the mouse maximal electroshock seizure (MES) model were of a pharmacokinetic nature. ${ }^{11}$ Only the interactions between indapamide and carbamazepine and valproate were pharmacodynamic in the mouse MES model, suggesting their clinical applicability in epilepsy patients. ${ }^{11}$ In the case of hydrochlorothiazide, the diuretic drug exclusively enhanced the anticonvulsant activity of carbamazepine in the mouse MES model.$^{10}$ As regards amiloride, the drug potentiated the anticonvulsant activity of carbamazepine, oxcarbazepine, phenobarbital, topiramate, and valproate in the mouse MES model. ${ }^{9}$ Unfortunately, amiloride pharmacokinetically potentiated the effects of carbamazepine, oxcarbazepine and phenobarbital in mice challenged with the MEST test. Only the pharmacodynamic interactions between amiloride and topiramate, and valproate deserve recommendation for their clinical use in epilepsy patients.

In conclusion, indapamide - with the lowest $\mathrm{TID}_{20}$ value in the mouse MEST test - deserves recommendation for clinical use as an add-on therapy in epilepsy patients who additionally require the application of diuretic drugs. 


\section{References}

1. Kearney PM, Whelton M, Reynolds K, Muntner P, Whelton PK, He J. Global burden of hypertension: Analysis of worldwide data. Lancet. 2005;365:217-223.

2. Kwan P, Schachter SC, Brodie MJ. Drug-resistant epilepsy. N Engl J Med. 2011;365:919-926.

3. Patsalos PN, Froscher W, Pisani F, van Rijn CM. The importance of drug interactions in epilepsy therapy. Epilepsia. 2002;43:365-385.

4. Doroszko A, Janus A, Szahidewicz-Krupska E, Mazur G, Derkacz A. Resistant hypertension. Adv Clin Exp Med. 2016;25:173-183.

5. Ali A, Ahmad FJ, Dua Y, Pillai KK, Vohora D. Seizures and sodium hydrogen exchangers: Potential of sodium hydrogen exchanger inhibitors as novel anticonvulsants. CNS Neurol Disord Drug Targets. 2008;7:343-347.

6. Kahle KT, Staley KJ. The bumetanide-sensitive Na-K-2Cl cotransporter NKCC1 as a potential target of a novel mechanism-based treatment strategy for neonatal seizures. Neurosurg Focus. 2008;25:E22. doi:10.3171/FOC/2008/25/9/E22

7. Löscher W, Puskarjov M, Kaila K. Cation-chloride cotransporters NKCC1 and KCC2 as potential targets for novel antiepileptic and antiepileptogenic treatments. Neuropharmacology. 2013;69:62-74.

8. Xiong ZG, Pignataro G, Li M, Chang SY, Simon RP. Acid-sensing ion channels (ASICS) as pharmacological targets for neurodegenerative diseases. Curr Opin Pharmacol. 2008;8:25-32.

9. Luszczki JJ, Sawicka KM, Kozinska J, Dudra-Jastrzebska M, Czuczwar SJ. Amiloride enhances the anticonvulsant action of various antiepileptic drugs in the mouse maximal electroshock seizure model. $J$ Neural Transm. 2009;116:57-66.

10. Lukawski K, Swiderska G, Czuczwar SJ. Effect of hydrochlorothiazide on the anticonvulsant action of antiepileptic drugs against maximal electroshock-induced seizures in mice. Pharmacol Rep. 2012;64: 315-320.

11. Kozinska J, Sawicka KM, Zadrozniak A, et al. Indapamide enhances the protective action of carbamazepine, phenobarbital, and valproate against maximal electroshock-induced seizures in mice. Adv Med Sci. 2009;54:66-74.

12. Swinyard EA, Brown WC, Goodman LS. Comparative assays of antiepileptic drugs in mice and rats. J Pharmacol Exp Ther. 1952;106:319-330.
13. Löscher W, Fassbender CP, Nolting B. The role of technical, biological and pharmacological factors in the laboratory evaluation of anticonvulsant drugs. II. Maximal electroshock seizure models. Epilepsy Res. 1991;8:79-94.

14. National Research Council (US) Committee for the Update of the Guide for the Care and Use of Laboratory Animals. Guide for the Care and Use of Laboratory Animals. $8^{\text {th }}$ ed. Washington, DC: National Academies Press US; 2011.

15. Kondrat-Wróbel MW, Luszczki JJ. Interaction of three-drug combination of lacosamide, carbamazepine and phenobarbital in the mouse maximal electroshock-induced seizure model: An isobolographic analysis. Health Probl Civiliz. 2016;10:55-61.

16. Litchfield JT Jr, Wilcoxon F. A simplified method of evaluating doseeffect experiments. J Pharmacol Exp Ther. 1949;96:99-113.

17. Luszczki JJ, Czuczwar SJ. Isobolographic characterization of interactions between vigabatrin and tiagabine in two experimental models of epilepsy. Prog Neuropsychopharmacol Biol Psychiatry. 2007;31: 529-538.

18. Luszczki JJ, Ratnaraj N, Patsalos PN, Czuczwar SJ. Isobolographic and behavioral characterizations of interactions between vigabatrin and gabapentin in two experimental models of epilepsy. EurJPharmacol. 2008;595:13-21.

19. Luszczki JJ, Czuczwar SJ. How significant is the difference between drug doses influencing the threshold for electroconvulsions? Pharmacol Rep. 2005;57:782-786.

20. Luszczki JJ, Dudra-Jastrzebska M, Andres-Mach M, et al. Stiripentol in a dose-dependent manner elevates the threshold for maximal electroshock-induced seizures in mice. JPCCR. 2007;1:155-157.

21. Reagan-Shaw $S$, Nihal $M, A$ Ahmad N. Dose translation from animal to human studies revisited. FASEB J. 2008;22:659-661.

22. Drugs.com. Indapamide dosage. http://www.drugs.com/dosage/ indapamide.html. Updated August 5, 2016. Accessed March 6, 2018.

23. Drugs.com. Amiloride dosage. http://www.drugs.com/dosage/ amiloride.html. Updated March 8, 2016. Accessed March 6, 2018.

24. Drugs.com. Hydrochlorothiazide dosage. http://www.drugs. com/dosage/hydrochlorothiazide.html. Updated August 9, 2016. Accessed March 6, 2018. 